\title{
Use of neurally adjusted ventilatory assist (NAVA) in a patient with severe SARS-CoV-2 pneumonia: A case report
}

\author{
Jeffrey M. Haynes RRT, RPFT, FAARC
}

\begin{abstract}
JM Haynes. Use of neurally adjusted ventilatory assist (NAVA) in a patient with severe SARS-CoV-2 pneumonia: A case report. Can J Respir Ther 2021;57:90-92. doi: 10.29390/cjrt-2021-017.

Introduction: Severe acute respiratory syndrome coronavirus 2 (SARS-CoV-2) pneumonia may necessitate intubation and prolonged mechanical ventilation. Early in the course of mechanical ventilation neuromuscular blocking agents may be used to allow synchronous lung protective ventilation. However, patients with SARS-CoV-2 pneumonia tend to have an intense respiratory drive resulting in patient-ventilator asynchrony when neuromuscular blocking agents are discontinued.

Case and Outcomes: A 75-year-old male was admitted to the hospital with SARS-CoV-2 pneumonia requiring invasive mechanical ventilation. By ventilator day 5 the neuromuscular blocking agent had been discontinued, and the patient was markedly asynchronous in the volume control mode despite receiving continuous intravenous sedatives. The ventilator mode was changed to the neurally adjusted ventilatory assist (NAVA) mode. Initially NAVA resulted in improved synchrony and reduced work of breathing. However, a few days later the patient's tidal volume had fallen to <300 mL on NAVA despite increases in the NAVA level. It appeared that the inspiratory phase was prematurely terminating, and the expiratory threshold in NAVA is not adjustable. The ventilator mode was changed to pressure support resulting in an increased tidal volume and reduced respiratory frequency.

Conclusion: In patients with SARS-CoV-2 pneumonia and intense respiratory drive, the performance of NAVA may be variable. NAVA may result in hypopnea and tachypnea when compared with pressure support. An assessment of the impact of an adjustable expiratory threshold in NAVA is warranted.
\end{abstract}

Key Words: respiratory failure; mechanical ventilation; neutrally adjusted ventilatory assist; COVID-19; SARS-CoV-2; case report

\section{INTRODUCTION}

Severe acute respiratory syndrome coronavirus 2 (SARS-CoV-2) pneumonia may necessitate intubation and prolonged mechanical ventilation. Early in the course of mechanical ventilation neuromuscular blocking agents may be used to allow synchronous lung protective ventilation. However, patients with SARS-CoV-2 pneumonia tend to have an intense respiratory drive resulting in patient-ventilator asynchrony when neuromuscular blocking agents are discontinued. This case describes the use of the neurally adjusted ventilatory assist (NAVA) mode to manage a patient with SARS-CoV-2 pneumonia and marked patient-ventilator asynchrony.

\section{Case description}

This work did not require review committee approval because a single case report or case series does not constitute human subjects research requiring review and approval.

A 75-year-old male resident of a long-term care facility was admitted to the hospital after a 2-week history of fever, chills, and congested cough. The patient had chronic obstructive pulmonary disease and emphysema chronically requiring supplemental $\mathrm{O}_{2}$ at $2 \mathrm{~L} / \mathrm{min}$ via nasal cannula. A chest radiograph revealed bilateral infiltrates and a nasopharyngeal swab culture tested positive for SARS-CoV-2.

The patient was intubated on hospital day 2 due to increasing dyspnea and $\mathrm{O}_{2}$ requirements. The ventilator settings immediately after intubation were as follows: volume control mode, set rate $18 \mathrm{~b} / \mathrm{min}$, tidal volume $\left(\mathrm{V}_{\mathrm{T}}\right)$ $450 \mathrm{~mL}\left(6 \mathrm{~mL} / \mathrm{kg}\right.$ ), positive end-expiratory pressure (PEEP) $5 \mathrm{~cm} \mathrm{H} \mathrm{H}_{2} \mathrm{O}$, and $\mathrm{FIO}_{2}$ 100\% (Servo-i, Getinge, Maquet Critical Care AB, Solna Sweden). Blood gas data on these settings were: $\mathrm{pH} 7.35, \mathrm{PaCO}_{2} 39 \mathrm{~mm}$
$\mathrm{Hg}, \mathrm{PaO}_{2} 200 \mathrm{~mm} \mathrm{Hg}$, and $\mathrm{O}_{2} \mathrm{Hb} 98 \%$. The $\mathrm{PaO}_{2} / \mathrm{FIO}_{2}$ ratio was 200 compatible with mild to moderate acute respiratory distress syndrome (ARDS) according to the Berlin definition [1]. The initial static respiratory compliance was $61 \mathrm{~mL} / \mathrm{cm} \mathrm{H}_{2} \mathrm{O}$ compatible with the proposed " $\mathrm{L}$ " phenotype of SARS-CoV-2 pneumonia [2]; however, the patient's emphysema presumably contributed to a finding of "normal" compliance.

By ventilator day 5 , chemical neuromuscular blockade had been discontinued. The patient's level of sedation was -3 on the Richmond Agitation and Sedation Scale while receiving continuous intravenous infusions of fentanyl and propofol. Despite sedation the patient remained in respiratory distress on volume control ventilation. Flow delivery had been changed to the square waveform with "flow support", which allows the patient to receive additional flow if the airway pressure falls $3 \mathrm{~cm} \mathrm{H} \mathrm{H}_{2} \mathrm{O}$ during the inspiratory phase of ventilation. An oral-gastric tube with embedded electromyogram electrodes (Edi catheter, Getinge, Maquet Critical Care AB, Solna Sweden) was inserted to monitor diaphragmatic activity and assess patient-ventilator synchrony. Proper positioning of the Edi catheter was confirmed using the Edi catheter positioning function. Despite the use of square waveform gas delivery with flow support, Figure 1 shows marked asynchrony with inspiratory pressure falling below PEEP during $V_{T}$ delivery and pressure spikes at the termination of the inspiratory phase. The mean airway pressure was identical to the PEEP level, which would be expected during unassisted ventilation with continuous positive airway pressure. The negative deflections in airway pressure due to volume starvation may be injurious due to a Pendelluft effect $[3,4]$. The electrical activity of the diaphragm (EAdi) was $25-30 \mu \mathrm{V}$,

Respiratory Therapy Department, St. Joseph Hospital, Nashua, NH, USA.

Correspondence: Jeffrey M. Haynes, RRT RPFT FAARC, Respiratory Therapy Department, St. Joseph Hospital, 172 Kinsley St., Nashua, NH 03060 , USA.

Tel: 1603595 3074,E-mail: jhaynes3@comcast.net

Published online at https://www.cjrt.ca on 22 July 2021

This open-access article is distributed under the terms of the Creative Commons Attribution Non-Commercial License (CC BY-NC) (http:// creativecommons.org/licenses/by-nc/4.0/), which permits reuse, distribution and reproduction of the article, provided that the original work is properly cited and the reuse is restricted to noncommercial purposes. For commercial reuse, contact editor@csrt.com 


\section{FIGURE 1}

Ventilator graphics from a patient with severe acute respiratory syndrome coronavirus 2 (SARS-CoV-2) pneumonia receiving volume control ventilation. Airway pressures (yellow tracing) falling below PEEP during the inspiratory cycle. The electrical activity of the diaphragm (EAdi; white tracing) shown in the bottom graphic and is superimposed over the airway pressure tracing.

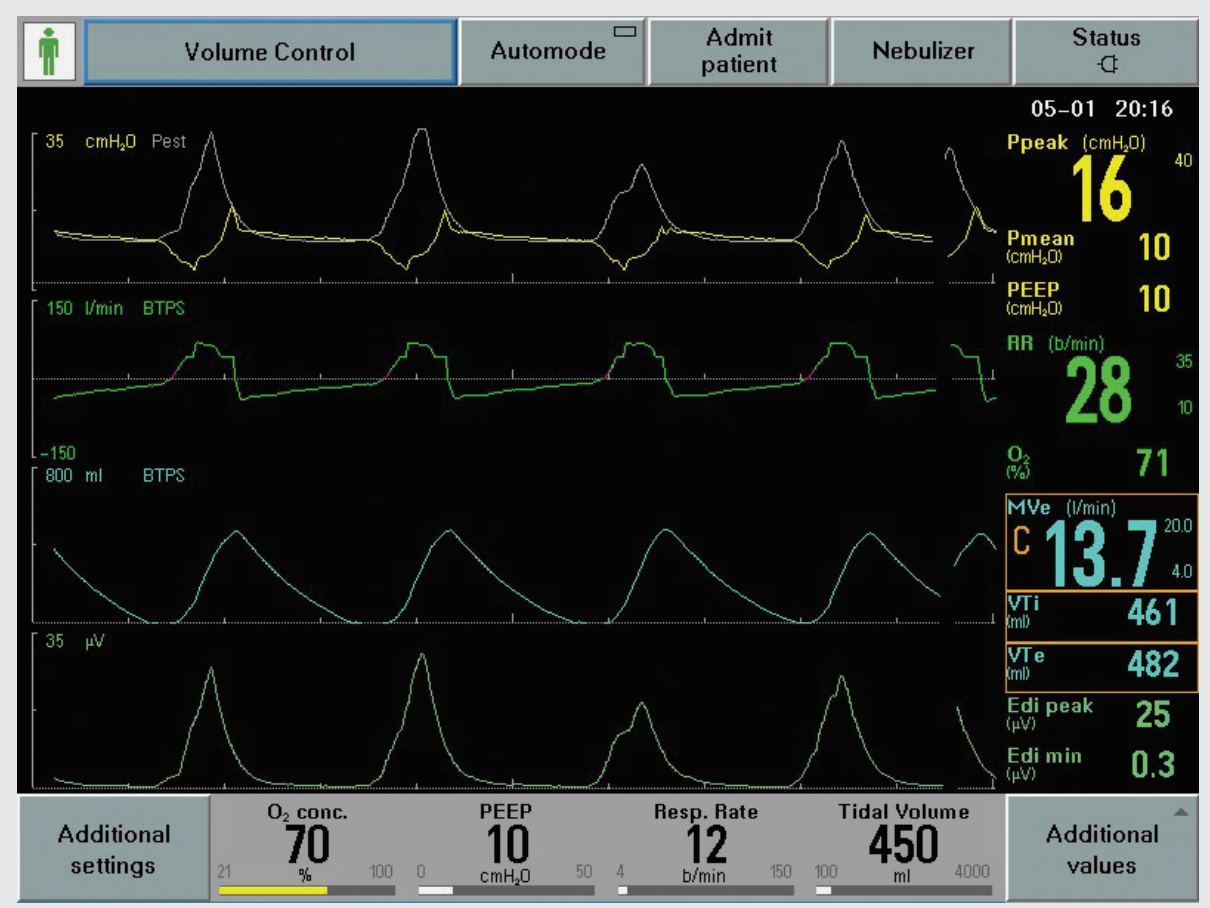

\section{FIGURE 2}

Ventilator graphics after the ventilator mode was changed to the neurally adjusted ventilatory assist (NAVA) mode.

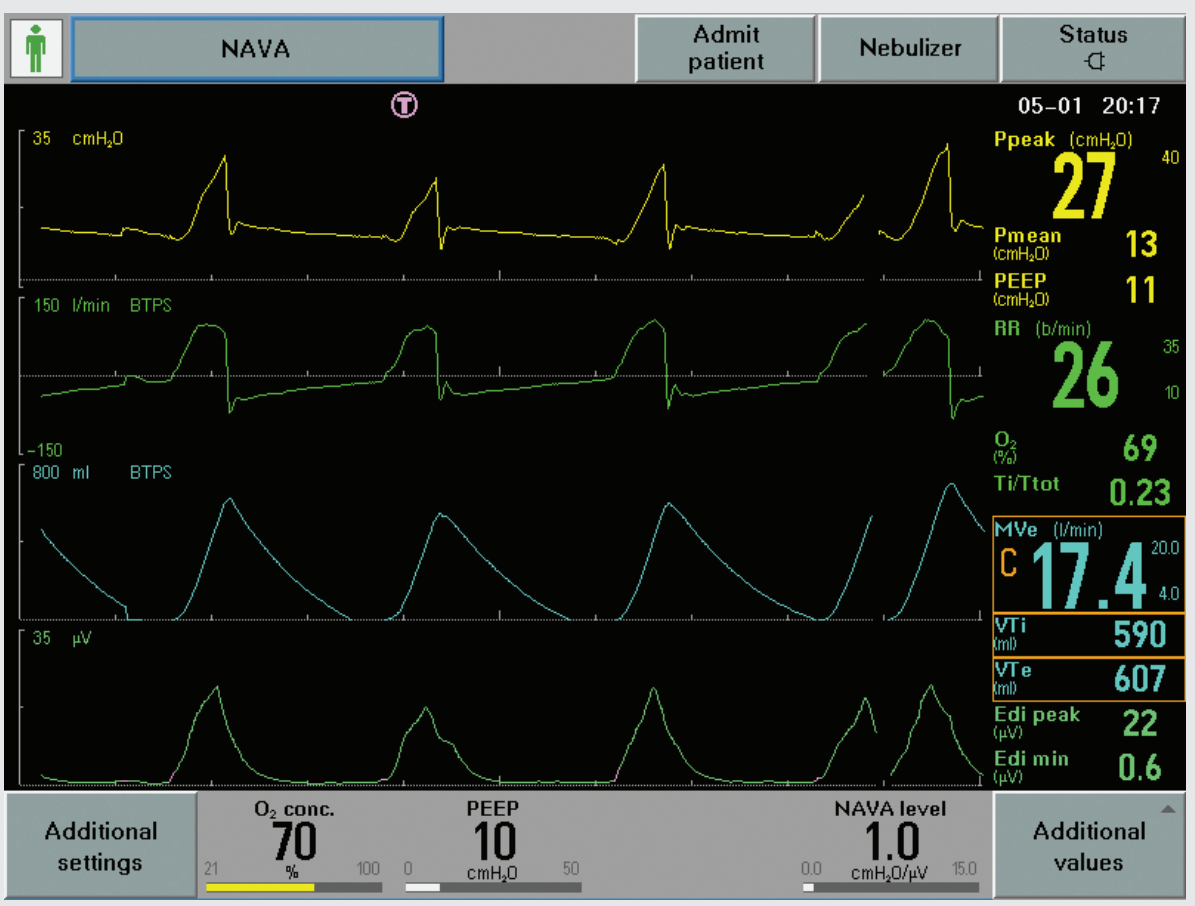


suggesting elevated respiratory drive and work of breathing [5]. In Figure 1 the EAdi waveform is superimposed over the pressure waveform as a preview of what the pressure waveform might be when changed to the NAVA mode. However, this overlay can be misleading because a NAVA breath terminates at $70 \%$ of the EAdi peak, where the preview graphic overlays the entire EAdi cycle over the airway pressure graphic. The ventilator mode was changed to NAVA at $1 \mathrm{~cm} \mathrm{H}_{2} \mathrm{O}$ per EAdi $\mu$ V. Figure 2 shows the ventilator graphics after the change to the NAVA mode. In NAVA the inspiratory airway pressure rose above PEEP, the $\mathrm{V}_{\mathrm{T}}$ increased to $\approx 600 \mathrm{~mL}(8 \mathrm{~mL} / \mathrm{kg})$, with an increase in minute ventilation and decrease in EAdi. A few days later the patient's $\mathrm{V}_{\mathrm{T}}$ had fallen to $<300 \mathrm{~mL}$ on NAVA despite increases in the NAVA level. It appeared that the inspiratory phase was prematurely terminating, and the expiratory threshold in NAVA (70\% of EAdi peak) is not adjustable. The ventilator mode was changed to pressure support with an expiratory flow sensitivity of $30 \%$. The change to pressure support increased the $\mathrm{V}_{\mathrm{T}}$ and reduced respiratory frequency.

\section{DISCUSSION}

Patients with SARS-CoV-2 pneumonia tend to have an intense respiratory drive [2,6], which may be due to known mechanisms [7] and perhaps amplified by other mechanisms such as neurotropism with the SARS-CoV-2 virus [8]. It has been our experience that most of these patients do poorly in volume control ventilation or dual control modes (e.g., pressure regulated volume control) without neuromuscular blockade because of this intense respiratory drive. Prolonged neuromuscular blockade is not associated with improved outcomes in ARDS [9] and patient-ventilator asynchrony is associated with numerous adverse effects [10]. An alternative strategy is to use partial ventilatory modes or pressure control ventilation. The trade-off of using partial ventilatory support modes to achieve better patient-ventilator synchrony is the risk of volutrauma and self-inflicted lung injury due to loss of $\mathrm{V}_{\mathrm{T}}$ control. This may be particularly worrisome in NAVA because the inspiratory pressure and volumes are based on the NAVA setting and EAdi peak value $\left(\mathrm{cm} \mathrm{H}_{2} \mathrm{O}\right.$ per EAdi $\left.\mu \mathrm{V}\right)$. So if the NAVA setting is $1 \mathrm{~cm}$ $\mathrm{H}_{2} \mathrm{O}$ per EAdi $\mu \mathrm{V}$, and the patient has an EAdi of $50 \mu \mathrm{V}$ (e.g., reduced sedation or stimulation) a breath with an inspiratory pressure of $50 \mathrm{~cm}$ $\mathrm{H}_{2} \mathrm{O}$ will be delivered. For this reason, it is important to maintain a tight high-pressure alarm setting and consider using conservative settings (i.e., low $\mathrm{cm} \mathrm{H}_{2} \mathrm{O}$ per EAdi $\mu \mathrm{V}$ ) when using NAVA in these types of patients. This risk may be associated with other modes like proportional assist ventilation that augments airway pressure based on patient effort. It is typically very easy to keep airway pressures "safe" (i.e., peak inspiratory pressure $<30 \mathrm{~cm} \mathrm{H}_{2} \mathrm{O}$ ) when using other partial ventilatory support modes; however, clinicians may have a false sense of security since the transpulmonary pressures might be indeed injurious even if the measured airway pressures are considered low [4].

In addition, as this case shows, even NAVA, a mode designed to minimize asynchrony, needed to be changed to pressure support to deliver more effective ventilation in a patient with SARS-CoV-2 pneumonia. We have experienced this phenomenon in other SARSCoV-2 patients being ventilated in the NAVA mode. In some cases increasing sedation improved problems with hypopnea associated with short inspiratory times in NAVA; however, in some of these cases the increase in sedation led to reduced respiratory rate and minute ventilation. In these situations we have found pressure support and pressure control modes to be good alternatives to NAVA. An assessment of the impact of an adjustable expiratory threshold in NAVA is warranted. In a study of non-CoV-2 infected ARDS patients, Diniz-Silva et al. [11] found no difference in respiratory rate and $V_{T}$ in patients being ventilated in NAVA or pressure support. This report suggests that NAVA and pressure support may perform differently in patients with SARS-CoV-2 pneumonia.

Clinicians caring for mechanically ventilated patients with SARSCoV-2 pneumonia will need to carefully balance patient-ventilator synchrony and the risk of volutrauma when selecting ventilator settings.
Titrating sedation to respiratory effort instead of focusing on consciousness alone may improve synchrony. Objective measures of respiratory drive including EAdi and airway occlusion pressure $\left(\mathrm{P}_{0.1}\right)$ may be helpful when titrating sedation [7]. Clinicians should also be prepared to change approaches according to the patient's response to support and evolving pathophysiology.

\section{CONCLUSION}

In patients with SARS-CoV-2 pneumonia and intense respiratory drive, the performance of NAVA may be variable. NAVA may result in hypopnea and tachypnea when compared with pressure support. An assessment of the impact of an adjustable expiratory threshold in NAVA is warranted.

\section{DISCLOSURES}

\section{Competing interests}

The author is a paid consultant for Morgan Scientific Inc., a pulmonary function test manufacturer, which would not influence the content of this submission.

\section{Funding}

This study did not receive any specific grant from funding agencies in the public, commercial, or not-for-profit sectors.

\section{Ethical approval}

This work did not require review committee approval for experimental study on human participants and/or confirmation of clinical trial registration because a single case report or case series (three or fewer cases) does not constitute human subjects research requiring review and approval.

\section{REFERENCES}

1. The ARDS Definition Task Force. Acute respiratory distress syndrome: the Berlin definition. JAMA 2012;307(23):2526-33. doi: 10.1001/ jama.2012.5669.

2. Marini JJ, Gattinoni L. Management of COVID-19 respiratory distress. JAMA 2020;323(22):2329-30. doi: 10.1001/jama.2020.6825.

3. Enokidani Y, Uchiyama A, Yoshida T, et al. Effects of ventilatory settings on Pendelluft phenomenon during mechanical ventilation. Respir Care 2021;66(1):1-10. doi: 10.4187/respcare.07880.

4. Yoshida T, Uchiyama A, Fujino Y. The role of spontaneous effort during mechanical ventilation: normal lung versus injured lung. J Intensive Care 2015;3:18. doi: 10.1186/s40560-015-0083-6.

5. Piquilloud L, Beloncle F, Richard JM, Mancebo J, Mercat A, Brochard L. Information conveyed by electrical diaphragmatic activity during unstressed, stressed and assisted spontaneous breathing: a physiological study. Ann Intensive Care 2019;9(1):89. doi: 10.1186/s13613-019-0564-1.

6. Worsham CM, Banzett RB, Schwartzstein RM. Air hunger and psychological trauma in ventilated COVID-19 patients: an urgent problem. Ann Am Thorac Soc 2020;17(8):926-7. doi: 10.1513/AnnalsATS. 202004-322VP.

7. Vaporidi K, Akoumianaki E, Telias I, Goligher EC, Brochard L, Georgopoulos D. Respiratory drive in critically ill patients. Pathophysiology and clinical implications. Am J Respir Crit Care Med 2020;201(1):20-32. doi: 10.1164/rccm.201903-0596SO.

8. Montalvan V, Lee J, Bueso T, De Toledo J, Rivas K. Neurological manifestations of COVID-19 and other coronavirus infections: a systematic review. Clin Neurol Neurosurg 2020;194:105921. doi: 10.1016/j.clineuro.2020. 105921.

9. National Heart, Lung, and Blood Institute PETAL Clinical Trials Network, Moss M, Huang DT, et al. Early Neuromuscular blockade in the acute respiratory distress syndrome. N Engl J Med 2019;380(21): 1997-2008. doi: 10.1056/NEJMoa1901686.

10. Epstein, SK. How often does patient-ventilator asynchrony occur and what are the consequences? Respir Care 2011;56(1):25-35. doi: 10.4187/ respcare.01009.

11. Diniz-Silva F, Moriya HT, Alencar AM, Amato MB, Carvalho CR, Ferreira JC. Neurally adjusted ventilatory assist vs. pressure support to deliver protective mechanical ventilation in patients with acute respiratory distress syndrome: a randomized crossover trial. Ann Intensive Care 2020;10(1): 18. doi: 10.1186/s13613-020-0638-0. 